\title{
SENSITIVITY OF C-BAND BACKSCATTER TO SURFACE ROUGHNESS PARAMETERS MEASURED AT DIFFERENT SCALES
}

\author{
Alex Martínez-Agirre ${ }^{(1)}$, Jesús Álvarez-Mozos ${ }^{(1)}$,Hans Lievens $^{(2)}$, Niko E.C. Verhoest $^{(2)}$ and Rafael \\ Giménez $^{(1)}$
}

(1) Public University of Navarre, Department of Projects and Rural Engineering, Los Olivos, Arrosadia, 31006, Pamplona, Spain, E-mail: alejandro.mda@unavarra.es

(2) Ghent University, Laboratory of Hydrology and Water Management, Coupure links 653, B-9000

Ghent, Belgium

\begin{abstract}
SAR (Synthetic Aperture Radar) sensors measure the backscatter $\left(\sigma^{0}\right)$ of land covers and SAR images have a number of applications in agricultural soils (soil moisture, crop monitoring, etc.) but the surface roughness of these soils complicates their interpretation and determination of quantitative estimates of useful parameters. The aim of this study is to quantify the spatial variability of different roughness parameters and the sensitivity of $\sigma^{0}$ to them measured at different scales. Ten Envisat/ASAR images acquired between September 2004 and January 2005 on an agricultural area with 10 control plots are analyzed. 132 roughness profiles of $5 \mathrm{~m}$ length were measured, and 21 different parameters were calculated. The results show considerable differences in the spatial variability of the parameters and differed depending on the type of parameter in the correlation analysis. This study can be useful to identify roughness parameters and scales that maximize their sensitivity to C-band backscatter.
\end{abstract}

Index Terms - SAR, sensitivity, surface roughness, roughness parameters, different scales

\section{INTRODUCTION}

Soil moisture (SM) retrieval from Synthetic Aperture Radar (SAR) observations is strongly affected by surface roughness. Although some advancements have taken place in the last years, its parameterization is still the main difficulty for an operational SAR-based SM retrieval. Surface roughness for SAR applications is normally parameterized as a random single-scale isotropic process [1] represented by two parameters: (1) the rms height or standard deviation of surface heights (s) and (2) the correlation length (lACF); the shape of the autocorrelation function is normally assumed exponential. This parameterization is limited because of the spatial variability of the parameters and also because of their multi-scale nature [2]. Roughness description is further complicated on agricultural surfaces compared to natural ones. On agricultural surfaces, roughness can be very dynamic due to tillage operations [3] and also due to the enhanced susceptibility to soil erosion processes [4].

In other fields of soil science (mainly in soil hydrology), many other roughness parameters have been developed to more adequately represent particular processes where this variable is involved (e.g. surface water storage) [5]. These parameters measure or combine different roughness properties, and therefore, they might also provide some interesting information for SAR backscatter studies. The objective of this study is to evaluate the sensitivity of Cband backscatter observations to different surface roughness parameters measured at different scales, and hence to identify the roughness parameters and scales maximizing this sensitivity.

\section{MATERIALS AND METHODS}

\subsection{Test site and field campaign}

For this study, ten agricultural fields (with sizes ranging from 3 to 7 ha) were monitored between September 2004 and March 2005. Fields were located in La Tejería watershed, a 170 ha experimental agricultural watershed located in the province of Navarre (Spain), at coordinates $42^{\circ} 44^{\prime} 10.6^{\prime \prime} \mathrm{N}$ and $1^{\circ} 56^{\prime} 57.2^{\prime \prime} \mathrm{W}$. The watershed is mostly cultivated with rain-fed winter cereal crops (wheat, barley and oats), normally sown at the end of October and harvested at the end of June. Soil preparation operations are performed in September and October. The different tillage operations that have been taken into account in this study are (1) Moldboard Plough (MP); (2) Harrowed Rough (HR); (3) Harrowed Smooth (HS); (4) Planted (P) and, (5) Planted Compacted (PC).

Ground sampling consisted of soil moisture and surface roughness measurements taken on four points per field. Soil moisture was measured with a calibrated TDR probe. 
Surface roughness was measured using a 5-m long laser profilometer with a 5-mm sampling interval.

\subsection{Roughness parameters evaluated}

Using the above mentioned profiles different roughness parameters were calculated per field. Some of the parameters are descriptors of the vertical roughness component (further referred to as vertical parameters), i.e., standard deviation of the heights $(s)$ [1], limiting elevation difference $(L D)$ [6], sill of the semivariogram (Sill) [4] and Micro-relief index $(M I)$ [3]; some others of the horizontal component (further referred to as horizontal parameters), i.e., correlation length $\left(l_{A C F}\right)$ [1], initial slope of the autocorrelation function $\left(\rho^{\prime}(0)\right)$, limiting slope $(L S)$ [6], range of the semivariogram (Range) [4] and peak frequency $(F)$ [3]; some are mixed parameters that represent both components, i.e., Tortuosity $\left(T_{S}\right)$ [7], $Z_{S}$ [8], $Q$ [9], MIF [3] and Mean Upslope Depression index (MUD) [5]; and some represent fractal behavior, i.e., fractal dimensions calculated with the semivariogram method $\left(D_{S M V}\right)$ [10], with the root-meansquare method $\left(D_{R M S}\right)$ [10], with the box-counting method $\left(D_{B C}\right)$ [11], with the power-spectrum method $\left(D_{P S}\right)$ [11] and with the rescaled range method $\left(D_{R S}\right)$ [12], and cross-over length calculated with the semivariogram method $\left(l_{S M V}\right)$ and with the root-mean-square method $\left(l_{R M S}\right)$ [10].

\subsection{SAR data}

During the study period, 10 Envisat/ASAR (vv polarization) scenes were acquired over La Tejería watershed. Scenes were processed following standard procedures. Scenes were, (1) orthorectified, (2) calibrated and (3) speckle filtered. Mean backscatter coefficient values $\left(\sigma^{0}\right)$ were calculated for each field per date.

A two stage $\sigma^{0}$ normalization was applied to remove the influence of factors other than roughness on $\sigma^{0}$ values. First, a local incidence angle normalization was performed based on Lambert's law [1]. Next, a SM normalization was performed using SM ground measurements and assuming a linear relation with $\sigma^{0}\left(\mathrm{R}^{2}=0.91\right)$.

\subsection{Analysis}

First, a descriptive statistical analysis of each parameter was performed. Next, the behavior of roughness parameters depending on profile length was analyzed for each tillage class. Finally, the sensitivity of $\sigma^{0}$ to the different roughness parameters and profile lengths was evaluated using linear regression techniques.

\section{RESULTS AND DISCUSSION}

In the descriptive statistical analysis (Table 1) we can see that the parameters with higher variability are those obtained from the semivariogram (Sill and Range) and the correlation length $\left(l_{A C F}\right)$, while the less variables are the peak frequency (F) and those based on fractal theory.

TABLE 1

DESCRIPTIVE STATISTICAL ANALYSIS OF THE ROUGHNESS PARAMETERS. SD: STANDARD DEVIATION. VC: VARIATION COEFFICIENT.

\begin{tabular}{ccccc}
\hline Parameter & Mean & SD & VC & Range \\
\hline$s(\mathrm{~cm})$ & 2.358 & 1.044 & 0.443 & {$[0.845-7.121]$} \\
$L D(\mathrm{~cm})$ & 2.787 & 1.428 & 0.512 & {$[0.891-8.368]$} \\
Sill $\left(\mathrm{cm}^{2}\right)$ & 7.354 & 8.777 & 1.194 & {$[0.708-66.410]$} \\
$M I(\mathrm{~cm})$ & 1.833 & 0.841 & 0.459 & {$[0.618-5.757]$} \\
\hline$l_{A C F}(\mathrm{~cm})$ & 9.089 & 8.573 & 0.943 & {$[1.962-46.765]$} \\
$\rho^{\prime}(0)$ & 0.017 & 0.008 & 0.484 & {$[0.004-0.050]$} \\
$L S$ & 1.127 & 0.176 & 0.158 & {$[0.717-1.516]$} \\
Range $(\mathrm{cm})$ & 12.195 & 21.695 & 1.779 & {$[0.362-237.788]$} \\
$\left.F(\mathrm{~cm})^{-1}\right)$ & 0.171 & 0.019 & 0.114 & {$[0.131-0.219]$} \\
\hline$Z_{S}(\mathrm{~cm})$ & 0.944 & 0.665 & 0.704 & {$[0.056-3.251]$} \\
$Q(\mathrm{~cm} / 2)$ & 1.724 & 0.475 & 0.276 & {$[0.799-3.463]$} \\
$M I F$ & 0.304 & 0.118 & 0.387 & {$[0.108-0.844]$} \\
$M U D(\mathrm{~cm})$ & 0.968 & 0.384 & 0.397 & {$[0.361-2.487]$} \\
$T_{S}$ & 35.552 & 5.414 & 0.152 & {$[19.444-48.859]$} \\
\hline$D_{S M V}$ & 1.645 & 0.088 & 0.053 & {$[1.410-1.863]$} \\
$D_{R M S}$ & 1.501 & 0.080 & 0.053 & {$[1.319-1.700]$} \\
$D_{B C}$ & 1.363 & 0.049 & 0.036 & {$[1.251-1.485]$} \\
$D_{P S}$ & 1.599 & 0.049 & 0.031 & {$[1.500-1.721]$} \\
$D_{R S}$ & 1.224 & 0.039 & 0.032 & {$[1.148-1.326]$} \\
$l_{S M V}(\mathrm{~cm})$ & 0.254 & 0.041 & 0.162 & {$[0.178-0.411]$} \\
$l_{R M S}(\mathrm{~cm})$ & 0.110 & 0.008 & 0.074 & {$[0.087-0.217]$} \\
\hline & & & &
\end{tabular}

The behavior of a selection of roughness parameters (one for each type) depending on the profile length is shown in Figure 1. Vertical parameters (e.g. $s$ ) increased with increasing profile lengths, especially on rough tillage classes (e.g., MP). Horizontal parameters (e.g. $l_{A C F}$ ) were even more sensitive to profile length for all classes, but a greater variability was observed. Mixed parameters (e.g. MUD) were less sensitive to profile length. Fractal-based measures (e.g. $D_{S M V}$ ) slightly decreased with increasing profile lengths. In the correlation analysis, results differed depending on the type of parameter (Figure 2). For vertical parameters correlation was around 0.6 but decreased when profiles were shorter than $1 \mathrm{~m}$. For horizontal parameters we found a less homogeneous behavior, where $\rho^{\prime}(0)$ and $F$ showed a similar behavior to vertical parameters (correlation increasing for longer profiles), and conversely $l_{A C F}, L S$ and Range had very low correlations. Mixed parameters behaved quite similar to vertical parameters but with slightly lower correlation values, except for $M U D$. And finally, it is remarkable that fractal dimensions calculated with different methods (except for the re-scaled method) showed strong correlations with $\sigma^{0}$, as long as profiles were longer than $1 \mathrm{~m}$. 
FIGURE I

SENSITIVITY OF FOUR SELECTED ROUGHNESS PARAMETERS TO PROFILE LENGTH PER TILLAGE CLASS.
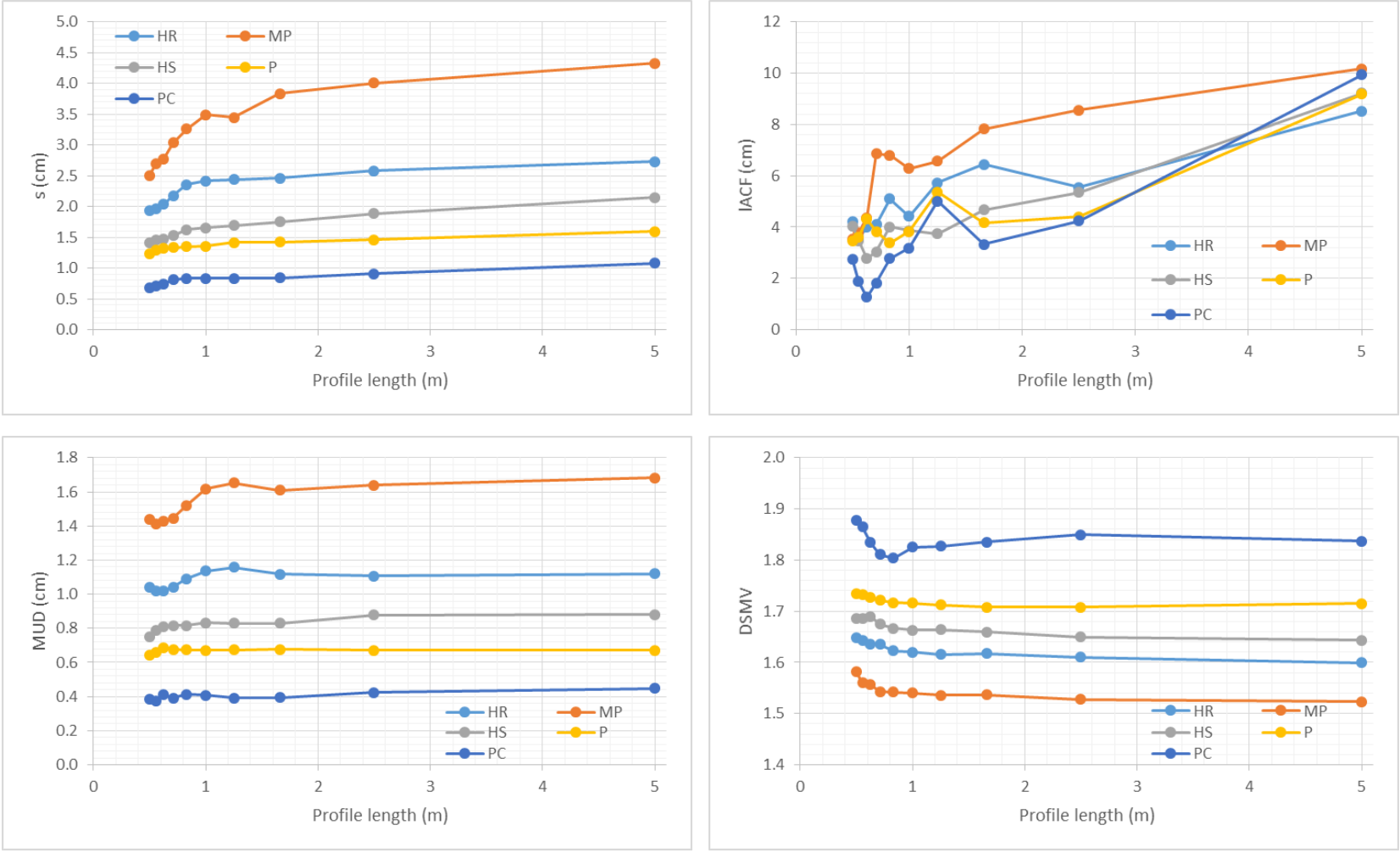

FIGURE II

CORRELATION BETWEEN $\sigma^{0}$ AND ROUGHNESS PARAMETERS DEPENDING ON PROFILE LENGTH. (A) VERTICAL PARAMETERS, (B) HORIZONTAL PARAMETERS, (C) MIXED PARAMETERS, AND (D) FRACTAL BEHAVIOR PARAMETERS.
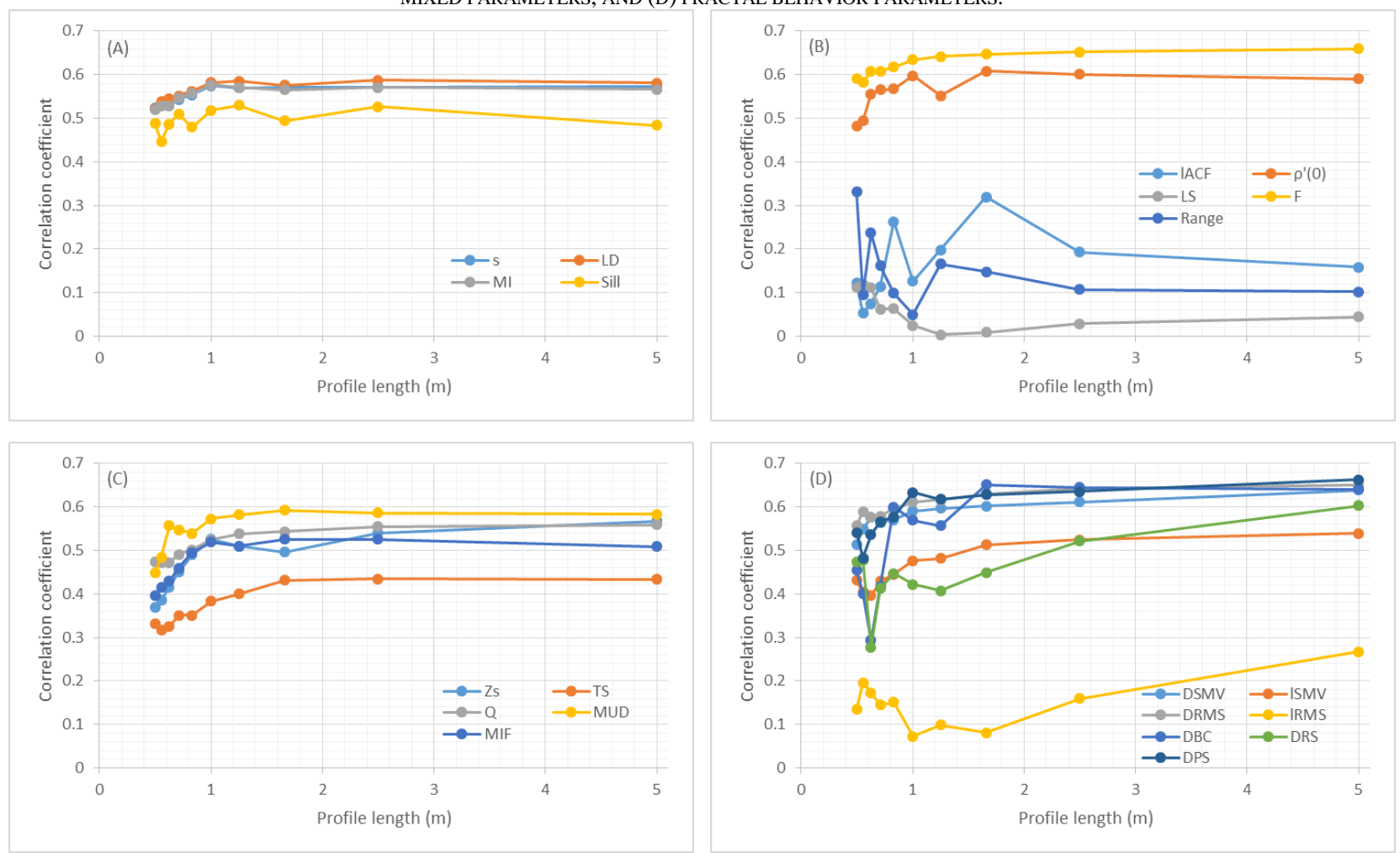


\section{CONCLUSIONS}

Although our results are preliminary, this analysis can be useful to identify roughness parameters and scales that maximize their sensitivity to C-band backscatter. Vertical parameters (except Sill) and the mixed parameter MUD show good correlation values (0.6), but fractal dimensions calculated by the different methods (except for the "ReScaled range") and above all, the horizontal parameter $F$ show higher correlation values with $\sigma^{0}$. Overall, the correlation values are stabilized from profile lengths higher than 1.25 or $1.66 \mathrm{~m}$. It is hoped that this study will contribute to understanding the phenomenon of backscattering in agricultural soils and the development of operating algorithms in the future.

\section{REFERENCES}

[1] F.T. Ulaby, R.K. Moore, and A.K. Fung, Microwave Remote Sensing, Active and Passive, Volume II: Radar Remote Sensing and Surface Scattering and Emission Theory, Artech House: Boston, MA, 1982.

[2] N.E.C. Verhoest, H. Lievens, W. Wagner, J. ÁlvarezMozos, M.S. Moran, and F. Mattia, "On the Soil Roughness Parameterization Problem in Soil Moisture Retrieval of Bare Surfaces from Synthetic Aperture Radar", Sensors, 8, 42134248, 2008.

[3] M.J.M. Römkens and J.Y. Wang, "Effect of Tillage on Surface Roughness", Trans. ASAE. 29(2): 429-433, 1986.

[4] K. Helming, Ch.H. Roth, R. Wolf, and H. Diestel, "Characterization of rainfall - Microrelief interactions with runoff using parameters derived from digital elevation models (DEMs)", Soil Technol, 6: 273-286, 1993.
[5] B. Hansen, P. Schjønning, and E. Sibbesen, "Roughness indices for estimation of depression storage capacity of tilled soil surfaces", Soil Tillage Res., 52: 103-111, 1999.

[6] D.R. Linden and D.M. Van Doren Jr., "Parameters for characterizing tillage-induced soil surface roughness", Soil Sci. Soc. Am. J. 50: 1560-1565, 1986

[7] A. Saleh, "Soil roughness measurement, chain method", J. Soil Water Conserv., 48(6): 527-529, 1993.

[8] M. Zribi and M. Dechambre, "A new empirical model to retrieve soil moisture and roughness from C-band radar data", Remote Sens. Environ. 84: 42-52. 2002.

[9] D.R. Linden, D.M. Van Doren, Jr., and R.R. Allmaras, "A model of the effects of tillage-induced soil surface roughness on erosion", Proc. of the $11^{\text {th }}$ International Conference of the International Soil and Tillage Research Organization, Edinburgh, 1, pp. 373-378, 1988.

[10] E. Vidal Vázquez, J.G. Vivas Miranda, and A. Paz González, "Characterizing anisotropy and heterogeneity of soil surface microtopography using fractal models", Ecol. Model. 182: 337-353, 2005.

[11] T. Gneiting, H. Ševcíková, and D.B. Percival, "Estimators of fractal dimension: Assessing the roughness of time series and spatial data", Statistical Science, 27, 247$277,2012$.

[12] H.H. Liu and F.J. Molz, "Discrimination of fractional Brownian movement and fractional Gaussian noise structures in permeability and related property distribution with range analysis", Water Resour. Res., 32, 2601-2605, 1996. 